\title{
Immune-based Therapies for Non-small Cell Lung Cancer
}

\author{
HIND RAFEI $^{1}$, EHAB EL-BAHESH ${ }^{2}$, ANTOINE FINIANOS $^{3}$, SAMAH NASSEREDDINE $^{1}$ and IMAD TABBARA ${ }^{4}$ \\ ${ }^{1}$ Department of Internal Medicine, George Washington University School of \\ Medicine and Health Sciences, Washington, DC, U.S.A.; \\ ${ }^{2}$ Clearview Cancer Institute, Huntsville, AL, U.S.A.; \\ ${ }^{3}$ Keserwan Medical Center, Jounieh, Lebanon; \\ ${ }^{4}$ Division of Hematology/Oncology and GW Cancer Center, \\ George Washington University Medical Faculty Associates, Washington, DC, U.S.A.
}

\begin{abstract}
Lung cancer is the leading cause of cancerrelated death worldwide. Treatment of non-small cell lung cancer has evolved tremendously over the past decade. Specifically, immune checkpoint inhibitors have become an increasingly interesting target of pharmacological blockade. These immune inhibitors have shown promising results in front-line therapy and after failure of multiple lines, as well as in monotherapy and combination with other therapies. Vaccination in non-small cell lung cancer is also an emerging field of research that holds promising results for the future of immunotherapy in non-small cell lung cancer. This review presents a concise update on the most recent data regarding the role of checkpoint inhibitors as well as vaccination in non-small cell lung cancer.
\end{abstract}

Lung cancer is the leading cause of cancer-related death in males, and the second leading cause of death in females worldwide (1). Non-small cell lung cancer (NSCLC) accounts for $85 \%$ to $90 \%$ of all lung cancer. There are different subtypes of NSCLC that are grouped together because, until recently, the approach to treatment as well as prognosis was often similar. These subtypes are squamous cell carcinoma (SqNSCLC), adenocarcinoma, large cell carcinoma and more poorly differentiated variants (2). Squamous cell carcinoma constitutes about $25-30 \%$ of all

This article is freely accessible online.

Correspondence to: Imad Tabbara, MD, 2150 Pennsylvania Ave NW, Washington DC 20037, U.S.A. Tel: +1 2027412210, e-mail: itabbara@mfa.gwu.edu

Key Words: Non-small cell lung cancer, immunotherapy, checkpoint inhibitors, vaccine, review. lung cancer. It originates from the bronchial lining, and is often linked to a history of smoking. Adenocarcinoma represents around $40 \%$ of lung cancer. It emerges from mucus-secreting cells. While this type of cancer occurs mainly in current and former smokers, it is the most common type of lung cancer occurring in non-smokers. Large-cell carcinoma accounts for about $10 \%$ to $15 \%$ of lung cancer and tends to grow and spread quickly (1).

Treatment options for NSCLC have evolved tremendously over the past 15 years, especially with the advent of genetic and molecular techniques to characterize the driver mutations at the cellular level. Overall survival (OS) rates from lung cancer have been increasing slowly over the past decade for both men and women. This is mainly due to reduction in smoking over the past 50 years, although the decline in the rates of lung cancer in men started significantly before that in women (3). Several treatment modalities are being used including surgery, radiation therapy, chemotherapy, targeted therapy, laser therapy, photodynamic therapy, radiofrequency ablation, cryosurgery, electrocautery, and watchful waiting. New modalities are being tested in clinical trials and they include immunotherapy, combination therapies and chemoprevention (4). To date, there are no studies that evaluate the best sequence of available therapies, and as such, the choice of therapy is highly personalized and likely depends on the setting in which available drugs were investigated, stage of disease, cytogenetic or molecular profile, performance status, toxicities, and medical comorbidities.

For a long time, lung cancer has been considered to be non-immunogenic. However, after the success of immunotherapies in melanoma (5), there has been great interest and investigation in the immune checkpoint inhibitors in NSCLC. These immune inhibitors have shown promising results in front-line therapy and after failure of multiple lines, as well as in monotherapy and combination 
with other therapies. Vaccination in NSCLC is also an emerging field of research that holds promising results for the future of immunotherapy in NSCLC.

\section{Programmed Cell Death Protein 1 (PD-1) and Its Ligands in NSCLC}

PD-1 is a type I transmembrane protein expressed on the surface of macrophages, dendritic cells, and T- and B-cells. Programmed cell death ligand 1 and 2 (PD-L1 and PD-L2, respectively) both act on PD-1 $(6,7)$. PD-L2 is mainly expressed on macrophages and dendritic cells, limiting its effects on T-cell regulation. However, PD-L1 is expressed on the same cells that express PD-1. Some cancer cells also express PD-L1 (8). Approximately $60 \%$ of NSCLCs have PDL1 expression (9). After the major histocompatibility complex I (MHC I) on the tumor complexes with the T-cell receptor, there is a release of interferon- $\gamma$, which up-regulates expression of PD-L1 on the tumor. PD-L1 then binds to the cluster of differentiation 8 (CD8) T-cell PD-1 receptor, resulting in inhibition of the effector T-cell and evasion of the immune system. The currently approved PD-1-targeted agents include nivolumab, pembrolizumab, and atezolizumab. Nivolumab and pembrolizumab are humanized IgG4 monoclonal antibodies (mAbs) against PD-1. Most therapeutic mAbs are IgG1, which results in antibody-dependent T-cell-mediated cytotoxicity. This, however, would cause destruction of T-cells expressing PD-1; therefore, the IgG4 subtype bypasses this adverse effect (8). The anti-PD-L1 mAbs, durvalumab and atezolizumab, are IgG1, but have been designed to prevent antibody-dependent T-cell-mediated cytotoxicity (ADCC).

In addition to their novel mechanisms of action, immunotherapies have been proven to induce unique responses. The current method for assessing progression is by the Response Evaluation Criteria In Solid Tumors (RECIST) (10). It has been noted in studies involving immunotherapies that using this method to assess response is not adequate. While these agents have shown OS benefit, progression-free survival (PFS) benefit may not be seen in comparison to standard chemotherapy. This is thought to be due to tumor infiltration following initiation of immunotherapy that results in an increase in radiographic tumor burden. It has been appreciated that those with radiographic progression, 'pseudoprogression', still received benefit of continuing immunotherapy $(8,11)$. The time to treatment response for the checkpoint inhibitors has been about 2 months (12-16). There are newer assessment tools such as the immune-related response criteria. They have not been routinely utilized as the comparator arm for these immunotherapy studies as in chemotherapy, where progression has been traditionally evaluated with RECIST (17). There is also no standard PDL1 assay, and at this time, only pembrolizumab has a complementary assay (Dako 22C3 PD-L1) (18).

\section{Monotherapy in Advanced NSCLC}

Nivolumab. Nivolumab is a fully human IgG4 mAb that targets PD-1. Nivolumab interferes with the negative signaling triggered by binding of PD-1 to PD-L1 or PD-L2 and thus restores T-cell antitumor function $(19,20)$.

Nivolumab was initially investigated in a phase I study of 122 heavily pre-treated patients with advanced NSCLC who had received one to five systemic regimens in a phase I study, comparing 1,3 and $10 \mathrm{mg} / \mathrm{kg}$ doses every 2 weeks. This study showed that the $3 \mathrm{mg} / \mathrm{kg}$ dose was superior, having an objective response rate (ORR) of $32 \%$ (21). This dose was established as the optimal dose in another doseescalation cohort expansion phase I trial that evaluated 129 patients with advanced NSCLC with one to five prior regimens. Median OS was 9.9 months for the entire group, whereas it was 14.9 months in the 37 patients receiving 3 $\mathrm{mg} / \mathrm{kg}$ nivolumab, 9.5 months in patients with SqNSCLC and 18.2 months in patients with non-SqNSCLC. Only $14 \%$ of patients had grade 3-4 treatment-related adverse events (AEs), and the most common was fatigue (3\%), and three patients $(2 \%)$ died of pneumonitis (22).

In a phase II single-arm trial, 117 patients with advanced SqNSCLC who had received two or more prior therapies, nivolumab was administered as an intravenous infusion at $3 \mathrm{mg} / \mathrm{kg}$ every 2 weeks until disease progression or unacceptable AEs occurred. 17 out of 117 patients had an objective response, of which $13(77 \%)$ had an ongoing response at the time of analysis and the median duration of response was not reached. Thirty $(26 \%)$ out of 117 patients had stable disease, with a median duration of 6.0 months and the median OS was 8.2 months. Grade 3-4 treatmentrelated AEs occurred in $17 \%$ of patients; only one patient died of treatment-related pneumonia and one of ischemic stroke (12). Early data from CheckMate 153 also showed a promising ORR and manageable immune-associated toxicities for those patients who had also been treated with at least two prior systemic regimens (13).

As a second-line therapy for stage IIIB or IV SqNSCLC with disease recurrence after one prior platinum-containing regimen, in a phase III study, CheckMate 017, nivolumab was shown to be more efficacious than docetaxel. The median OS was 9.2 months $[95 \%$ confidence interval $(\mathrm{CI})=7.3$ to 13.3 months] with nivolumab versus 6.0 months (95\% CI=5.1 to 7.3 months) with docetaxel. The risk of death was $41 \%$ lower with nivolumab than with docetaxel (hazard ratio $=0.59 ; 95 \% \mathrm{CI}=0.44$ to $0.79 ; p<0.001$ ). At 1 year, the OS rate was $42 \%(95 \% \mathrm{CI}=34$ to $50 \%)$ with nivolumab versus $24 \%$ (95\% CI=17 to $31 \%$ ) with docetaxel. The response rate was $20 \%$ with nivolumab versus $9 \%$ with docetaxel $(p=0.008)$. The median PFS was 3.5 months with nivolumab versus 2.8 months with docetaxel (hazard ratio for death or disease progression $=0.62 ; 95 \% \mathrm{CI}=0.47$ to 0.81 ; 
Table I. Survival analysis in CheckMate 057 (15).

\begin{tabular}{|c|c|c|c|c|}
\hline \multirow[b]{2}{*}{ PD-L1 } & \multicolumn{2}{|c|}{$\begin{array}{c}\text { Median overall } \\
\text { survival (months) }\end{array}$} & \multirow[b]{2}{*}{$\mathrm{HR}(95 \% \mathrm{CI})$} & \multirow[b]{2}{*}{$p$-Value } \\
\hline & Nivolumab & Docetaxel & & \\
\hline$\geq 1 \%$ & 17.1 & 9.0 & $0.59(0.43-0.82)$ & 0.06 \\
\hline$<1 \%$ & 10.4 & 10.1 & $0.90(0.66-1.24)$ & 0.06 \\
\hline$\geq 5 \%$ & 18.2 & 8.1 & $0.43(0.30-0.63)$ & $<0.001$ \\
\hline$<5 \%$ & 9.7 & 10.1 & $1.01(0.77-1.34)$ & $<0.001$ \\
\hline$\geq 10 \%$ & 19.4 & 8.0 & $0.40(0.26-0.59)$ & $<0.001$ \\
\hline$<10 \%$ & 9.9 & 10.3 & $1.00(0.76-1.31)$ & $<0.001$ \\
\hline
\end{tabular}

PD-L1: Programmed death-ligand 1; HR: hazard ratio; CI: confidence interval.

$p<0.001)$. PD-L1 expression was neither prognostic nor predictive of any efficacy end-points (14).

In CheckMate 057, a multi-center phase III trial, nivolumab was compared to docetaxel as a second-line therapy in nonsquamous NSCLC. Nivolumab demonstrated superior OS $(\mathrm{HR}=0.73 ; 96 \% \mathrm{CI}=0.59,0.89 ; p=0.00155)$ and improved ORR (19.2\% vs. $12.4 \% ; p=0.0235)$. The median time to response was 2.1 months for nivolumab. The median PFS favored docetaxel over nivolumab, 4.2 months versus 2.3 months, respectively. However, the rate of progression at 1 year favored nivolumab, with a rate of $19 \%$, which was better than that with docetaxel (8\%). However, a subgroup of patients with advanced non-squamous NSCLC with PD-L1 expression less than $1 \%$ did not show a benefit of nivolumab to docetaxel (Table I). Despite the lack of superiority in this subgroup with regards to OS, it was not inferior and there were fewer AEs, still making nivolumab a desirable option over docetaxel (15). Following these results, nivolumab was approved by the US Food and Drug Administration (FDA) as second-line therapy for metastatic NSCLC with progression on or after standard therapy. PD-L1 testing was complementary and not required for nivolumab administration.

There are a few promising trials that are investigating the various clinical settings where nivolumab may be efficacious. The NICOLAS trial is now evaluating nivolumab as a consolidation monotherapy for locally advanced stage IIIA/B NSCLC that has not progressed after standard chemotherapy and radiotherapy (23). There is also a phase I trial investigating the role of nivolumab monotherapy in the front-line setting for advanced NSCLC (24). The median duration of response for the 52 enrolled patients had not yet been reached at the time the abstract was published (range $=7.6+-85.6+$ weeks). The median OS was 98.3 weeks (range $=1.0-104.4+$ weeks).

Pembrolizumab. Unlike nivolumab, which received nonrestricted FDA approval, pembrolizumab received accelerated approval with companion diagnostic PD-L1 assay of $1 \%$ or more for advanced NSCLC that progressed while on ongoing or after standard therapy. A phase I trial, KEYNOTE-001, enrolled 495 patients receiving pembrolizumab (at a dose of either 2 or $10 \mathrm{mg} / \mathrm{kg}$ every 3 weeks or $10 \mathrm{mg} / \mathrm{kg}$ every 2 weeks). There were $21 \%$ squamous and $75 \%$ non-squamous cases in this study. The pooled ORR was $19.4 \%$, with response rates of $18.0 \%$ and $24.8 \%$ in previously treated and untreated patients, respectively. Median PFS and OS were 3.0 and 9.3 months in treated patients, respectively, compared to 6.0 and 16.2 months in previously untreated patients. The response rates were similar regardless of dose or schedule. Common sideeffects that were attributed to pembrolizumab were fatigue, pruritus, and decreased appetite, with no clear difference according to dose or schedule (18). The efficacy was affected by high-level tumor staining of PD-L1, which prompted the phase II/III study KEYNOTE-010 prior to the completion of KEYNOTE-001. Therefore, in KEYNOTE-010, there were still two dosing regimens for pembrolizumab ( 2 and $10 \mathrm{mg} / \mathrm{kg}$ every 3 weeks) compared to docetaxel but there needed to be at least $1 \%$ expression of PD-L1. This study looked at PFS and OS for the entire population and those with 50\% or more PD-L1 expression. In those with any PD-L1 expression of $1 \%$ or more, the two pembrolizumab arms performed similarly in regards to OS (2 mg/kg dosing was 10.4 months and $10 \mathrm{mg} / \mathrm{kg}$ was 12.7 months). There was a clear benefit of pembrolizumab over docetaxel, which had a median OS of 8.5 months. The median PFS was about 4 months in all arms of the study. In those with $50 \%$ or more PD-L1 expression, the median OS in the $2 \mathrm{mg} / \mathrm{kg}$ (14.9 months) and $10 \mathrm{mg} / \mathrm{kg}$ (17.3 months) pembrolizumab arms was about double that with docetaxel ( 8.2 months). The median PFS in this high-expression group was about 5 months for pembrolizumab and 4 months for docetaxel, a statistically significant difference (25) (Table II). Pembrolizumab is also currently being investigated in a phase II trial as a consolidation therapy following initial treatment with concurrent chemoradiation in patients with inoperable or unresectable stage IIIA or IIIB NSCLC (26).

While there is currently a phase II study of pembrolizumab after high-dose radiation versus pembrolizumab alone in patients with advanced NSCLC (27), two other randomized, open-label, phase III studies, KEYNOTE-042 and KEYNOTE024 , have been designed to evaluate pembrolizumab as firstline monotherapy compared to platinum-based chemotherapy in patients with locally advanced or metastatic PD-L1-positive NSCLC $(28,29)$. KEYNOTE-024 results were recently published. The clinical trial compared pembrolizumab (at the fixed dose of $200 \mathrm{mg}$ every 3 weeks with the investigator's choice of chemotherapy as first-line treatment for patients with advanced NSCLC and 50\% or more tumor score for PD-L1. Pembrolizumab was associated with significantly longer PFS and OS. Median PFS was 10.3 months in the pembrolizumab group versus 6 months in the chemotherapy group $(p<0.001)$ 
Table II. Survival analysis in KEYNOTE-010 (25).

\begin{tabular}{lcc}
\hline Pembrolizumab-docetaxel therapy & PD-L1 $\geq 1 \%$ & PD-L1 $\geq 50 \%$ \\
\hline Pembrolizumab at 2 mg/kg every 3 weeks/docetaxel & & $14.9 / 8.2$ \\
Median OS, months & $10.4 / 8.5$ & $0.54(0.38-0.77), p=0.0002$ \\
HR (95\% CI) & $0.71(0.58-0.88), p=0.0008$ & $5.0 / 4.1$ \\
Median PFS, months & $3.9 / 4.0$ & $0.59(0.44-0.78), p=0.0001$ \\
HR (95\% CI) & $0.88(0.74-1.05), p=0.07$ & $17.3 / 8.2$ \\
Pembrolizumab at 10 mg/kg every 3 weeks/docetaxel & $12.7 / 8.5$ & $0.50(0.36-0.70), p<0.0001$ \\
Median OS, months & $0.61(0.49-0.75), p<0.0001$ & $5.2 / 4.1$ \\
HR (95\% CI) & $4.0 / 4.0$ & $0.59(0.45-0.78), p<0.0001$ \\
Median PFS, months & $0.79(0.66-0.94), p=0.004$ & \\
HR (95\% CI) &
\end{tabular}

PD-L1: Programmed death-ligand 1; OS: overall survival; HR: hazard ratio; PFS: progression-free survival.

and the estimated rate of OS at 6 months was $80.2 \%$ in the pembrolizumab group compared to $72.4 \%$ in the chemotherapy group $(p=0.005)(29)$.

Atezolizumab. Atezolizumab is an IgG1 antibody to PD-L1 that has refined to prevent ADCC) It was approved on October 18, 2016 by the FDA for the treatment of patients with PDL1-positive NSCLC whose cancer had progressed during or after standard treatment. The FDA approval was based on two trials, POPLAR and OAK. In POPLAR, a phase II study, atezolizumab was compared to docetaxel after first-line therapy of NSCLC. Patients were randomly allocated to the atezolizumab or docetaxel groups (142 vs. 135 patients). Intention-to-treat analysis showed an OS of 12.6 months with atezolizumab versus 9.7 months with docetaxel $(p=0.04)$. Increased OS was associated with increased PD-L1 expression (30). OAK was a phase III study that also compared atezolizumab to docetaxel, finding a median OS of 13.8 months in the atezolizumab group versus 9.6 months in the docetaxel group $(p=0.0004)$ (31).

A phase II study, FIR, of atezolizumab in PD-L1-selected patients with NSCLC showed clinical efficacy in both chemo-naive and previously treated NSCLC. High PD-L1 expression was associated with a higher ORR (32).

A phase II study, BIRCH, is also recruiting participants to observe the response to atezolizumab as first-, second-, and third-line therapy for patients with PD-L1-positive locally advanced or metastatic NSCLC (33).

Durvalumab. Durvalumab is another IgG1 antibody directed against PD-L1 that has been designed to prevent ADCC. ATLANTIC, a phase II trial, has been designed to evaluate the efficacy of durvalumab as third-line therapy in patients with locally advanced or metastatic NSCLC (34).

ARCTIC, however, is a global study to assess the effects of durvalumab given as monotherapy or in combination with tremelimumab, determined by PD-L1 expression, versus standard of care in patients with locally advanced or metastatic NSCLC (35).

BMS-936559. BMS-936559 is a fully human, PD-L1specific, IgG4 mAb that inhibits the binding of PD-L1 to both PD-1 and CD80. In a phase I trial for treatment of NSCLC with BMS-936559, there was an ORR of 10\%: 5 out of 49 patients with NSCLC, four with non-squamous and one with squamous type. Three of these patients had responses lasting at least 24 weeks. Stabilization of disease at 6 months took place in $12 \%$ of patients. In the overall population, grade 3 or 4 AEs occurred in $9 \%$ of patients (36).

Overall, and as evident with other immunotherapies, anti-PD-1 medications can be accompanied by a flare response. This is usually the case when the patient is clinically improving but radiographically has evidence of disease progression. This is usually transient and eventually responders will have disease stability or tumor regression. Moreover, in patients who stopped the drug after disease stability or response, response can still be seen if the drug is revisited upon progression (21). Tables III and IV summarize the completed and ongoing clinical trials, respectively, of PD-1/PD-L1 inhibitors as monotherapy in NSCLC.

\section{Combination with Chemotherapy in Advanced NSCLC}

Combination of PD-1/PD-L1 inhibition with standard chemotherapy has brought new hope to outcomes in advanced NSCLC. KEYNOTE-021 evaluated the safety, tolerability, and clinical activity of pembrolizumab combined with chemotherapy for treatment-naive advanced NSCLC. Patients with stage IIIB/IV NSCLC and no prior 
Table III. Clinical trials for programmed cell death protein 1/programmed cell death ligand 1 (PD-1/PD-L1) inhibitors as monotherapy in nonsmall cell lung cancer (NSCLC).

\begin{tabular}{|c|c|c|c|c|}
\hline Study name & Agent & Phase & Stage/line & Outcomes \\
\hline (21) & Nivolumab & I & $\begin{array}{l}\text { Advanced or recurrent } \\
\text { malignancies including }\end{array}$ & $\mathrm{ORR}=18.4 \%$ \\
\hline (22) & Nivolumab & I & Heavily pretreated advanced & ORR $=17 \%$, OS $=9.9$ months \\
\hline CheckMate 063 (12) & Nivolumab & II & $\begin{array}{l}\text { Advanced SqNSCLC previously } \\
\text { treated with } \geq 2 \text { regimen }\end{array}$ & $\mathrm{ORR}=14.5 \%$ \\
\hline CheckMate 017 (14) & Nivolumab & III & $\begin{array}{l}\text { Advanced or metastatic that progressed } \\
\text { during or after } \geq 1 \text { prior regimen }\end{array}$ & $\begin{array}{c}\text { ORR }=20 \% \text { vs. } 9 \% \\
\text { with docetaxel }\end{array}$ \\
\hline CheckMate 057 (15) & Nivolumab & III & $\begin{array}{l}\text { Non-sqNSCLC that progressed during } \\
\text { or after Pt-based regimen }\end{array}$ & $\begin{array}{c}\text { ORR }=19.2 \% \text { vs. } 12.4 \% \\
\text { with docetaxel }\end{array}$ \\
\hline KEYNOTE-001 (18) & Pembrolizumab & I & Locally advanced or metastatic & $\begin{array}{c}\text { Pooled ORR }=19.4 \%, \mathrm{RR}=18.0 \% \\
\text { and } 24.8 \% \text { in previously treated and } \\
\text { untreated patients, respectively }\end{array}$ \\
\hline KEYNOTE-010 (25) & Pembrolizumab & II/III & $\begin{array}{c}\text { Previously treated, PD-L1-positive, } \\
\text { advanced NSCLC }\end{array}$ & $\begin{array}{l}\text { Clear benefit, almost doubling of } \\
\text { OS compared with docetaxel }\end{array}$ \\
\hline KEYNOTE-024 (29) & Pembrolizumab & III & $\begin{array}{l}\text { Previously untreated, strong PD-L1- } \\
\text { expressing stage IV }\end{array}$ & $\begin{array}{c}\text { PFS }=10.3 \text { months vs. } 6 \text { months } \\
\text { with chemotherapy. OS at } 6 \\
\text { months }=80.2 \% \text { vs. } 72.4 \% \\
\text { with chemotherapy }\end{array}$ \\
\hline POPLAR (30) & Atezolizumab & II & Advanced or metastatic after Pt failure & $\begin{array}{l}\text { Median OS }=12.6 \text { months } v s \text {. } \\
9.7 \text { months with docetaxel }\end{array}$ \\
\hline OAK (31) & Atezolizumab & III & Advanced or metastatic after Pt failure & $\begin{array}{l}\text { Median OS }=13.8 \text { months } v s \text {. } \\
9.6 \text { months with docetaxel }\end{array}$ \\
\hline (36) & BMS-936559 & I & Locally advanced or metastatic & $\mathrm{ORR}=10 \%$ \\
\hline
\end{tabular}

ORR: Overall response rate; OS: overall survival; SqNSCLC: squamous; Non-sqNSCLC: non-squamous NSCLC; Pt: platinum; RR: response rate; PFS: progression-free survival.

systemic therapy were randomized to pembrolizumab plus carboplatin and paclitaxel (cohort $\mathrm{A}$; any histology) or carboplatin plus pemetrexed [cohort $\mathrm{C}$; nonsquamous without epidermal growth factor receptor $(E G F R)$ sensitizing mutation or anaplastic lymphoma kinase $(A L K)$ translocation only]. Preliminary ORR was $30 \%$ in cohort $\mathrm{A}$ and $58 \%$ in C (37). Some phase I/II studies are currently designed to investigate pembrolizumab in combination with chemotherapy for patients with advanced NSCLC $(38,39)$.

Atezolizumab (15 mg/kg intravenously every 3 weeks) in combination with chemotherapy as first-line therapy also showed promising clinical activity with well-tolerated toxicities. ORR was $67 \%$ in the 37 patients evaluated. The major drug-related toxicities included grade 3-4 AEs of anemia $(7 \%)$, neutropenia $(7-13 \%)$, and thrombocytopenia (7\%), while only one grade $5 \mathrm{AE}$ of candidemia was observed (40). Nivolumab combined with chemotherapy also led to similar outcomes. The results of the CheckMate 012 study of nivolumab plus chemotherapy in advanced NSCLC were as follows: ORR $33-47 \%$, median PFS 21.0-31.0 weeks, and 1-year OS rate $50-87 \%$. No treatment-related deaths occurred, but a treatment-related toxicity rate of $45 \%$ at grade $3 / 4$ was reported (16).

\section{Combination with Targeted Therapy}

EGFR tyrosine kinase inhibitors (TKIs), such as gefitinib, erlotinib and afatinib, are recommended as first-line therapy in EGFR-mutant advanced NSCLC. Combination therapy of PD1 pathway blockade and EGFR-TKIs has been shown to be promising by data from preclinical studies. It has been suggested that EGFR activation up-regulates expression of PDL1 and hence contributes to immune evasion $(41,42)$. A retrospective study that included 125 patients with NSCLC, including patients with mutant and wild-type $E G F R$, V-Ki-ras2 Kristen rat sarcoma viral oncogene homolog (KRAS) and $A L K$ all with PD-L1 expression found a correlation between PD-L1 expression and EGFR mutation (43). PD-L1- positive patients had higher sensitivity to EGFR-TKIs than PD-L1-negative patients in terms of the response rate $(p=0.01)$. Remarkably, PD-L1-positive tumors were significantly associated with adenocarcinoma histology $(p=0.005)$. Another retrospective study of 56 patients with EGFR-mutant advanced lung adenocarcinoma demonstrated a significantly higher diseasecontrol rate $(p=0.004)$, longer PFS $(p=0.001)$, and OS $(p=0.004)$ after TKI therapy in PD-L1-positive patients (44). A third retrospective analysis of 170 patients with advanced NSCLC treated with EGFR-TKIs indicated that PD-L1 
Table IV. Ongoing clinical trials for programmed cell death protein 1/programmed cell death ligand 1 (PD-1/PD-L1) inhibitors as monotherapy for non-small cell lung cancer (NSCLC).

\begin{tabular}{|c|c|c|c|c|c|c|}
\hline Study name & Study Identifier & Agent & Phase & Stage/line & Outcomes & Grade 3-4 AEs \\
\hline CheckMate 153 (13) & NCT02066636 & Nivolumab & $\mathrm{IIIb} / \mathrm{IV}$ & $\begin{array}{c}\text { Advanced or metastatic, } \\
\text { progressing after } \geq 1 \\
\text { prior regimen }\end{array}$ & No results yet & No results yet \\
\hline NICOLAS (23) & NCT02434081 & Nivolumab & II & $\begin{array}{c}\text { Stage IIIA/B not } \\
\text { progressing after } \\
\text { standard chemoradiation }\end{array}$ & No results yet & No results yet \\
\hline CheckMate 012 (16) & NCT01454102 & Nivolumab & I & Chemo-naïve advanced & $\begin{array}{c}\text { Median overall } \\
\text { survival=98.3 weeks }\end{array}$ & $\begin{array}{c}\text { Rash, increased amylase/ } \\
\text { lipase, increased } \\
\text { AST/ALT, hyperglycemia, } \\
\text { cardiac failure, } \\
\text { lung infection, and } \\
\text { pneumonitis }\end{array}$ \\
\hline LUN14-179 (26) & NCT02343952 & Pembrolizumab & II & $\begin{array}{l}\text { Unresectable stage } \\
\text { IIIA/B after chemoradiation }\end{array}$ & No results yet & No results yet \\
\hline PEMBRO-RT (27) & NCT02492568 & Pembrolizumab & II & Advanced & No results yet & No results yet \\
\hline KEYNOTE-042 (28) & NCT02220894 & Pembrolizumab & III & $\begin{array}{l}\text { PD-L1-positive advanced } \\
\text { or metastatic }\end{array}$ & No results yet & No results yet \\
\hline FIR (32) & NCT01846416 & Atezolizumab & II & $\begin{array}{l}\text { PD-L1-positive advanced } \\
\text { or metastatic }\end{array}$ & $\begin{array}{l}\text { Clinical efficacy in } \\
\text { both chemo-naive and } \\
\text { previously treated }\end{array}$ & $\begin{array}{c}\text { Fatigue, nausea, and } \\
\text { decreased appetite }\end{array}$ \\
\hline BIRCH (33) & NCT02031458 & Atezolizumab & II & $\begin{array}{l}\text { PD-L1-positive advanced } \\
\text { or metastatic }\end{array}$ & No results yet & No results yet \\
\hline ATLANTIC (34) & NCT02087423 & MEDI4736 & II & Locally advanced or metastatic & No results yet & No results yet \\
\hline ARCTIC (35) & NCT02352948 & MEDI4736 & III & Locally advanced or metastatic & No results yet & No results yet \\
\hline
\end{tabular}

AEs: Adverse events; ALT: alanine aminotransferase; AST: aspartate aminotransferase.

expression was associated with significantly shorter OS in patients with wild-type EGFR ( $p=0.029)$, but not in those with mutant EGFR ( $p=0.932$ ) (45). Combination therapy of PD-L1 blockade and EGFR-TKIs was investigated in an escalation phase I study where durvalumab was utilized along with gefitinib in two cohorts (cohort A: MEDI4736 at $3 \mathrm{mg} / \mathrm{kg}$ every 2 weeks and cohort B at $10 \mathrm{mg} / \mathrm{kg}$ every 2 weeks). Data showed that the maximum tolerated dose was not reached and no drugrelated toxicities were observed. Grade 3-4 AEs were observed in three patients, including dyspnea/hypoxia, myalgia/fatigue, and elevated alanine aminotransferase level (46).

Bevacizumab is a recombinant mAb that works as antiangiogenesis therapy by blocking the vascular endothelial growth factor (VEGF). It is recommended in combination with platinum-doublet chemotherapy for locally advanced or metastatic non-SqNSCLC as first-line therapy or monotherapy maintenance. For patients who have previously responded to bevacizumab, maintenance with bevacizumab as monotherapy is recommended. Data from the AVAPERL study demonstrated that PFS and median OS for patients treated with single-agent bevacizumab were 3.7 and 13.2 months, respectively (47). A phase I study evaluated the efficacy of nivolumab with and without bevacizumab maintenance in patients with advanced NSCLC which did not progress during or after first-line platinum-based chemotherapy. Median PFS was 37.1 weeks with nivolumab and bevacizumab combination therapy, with the median OS not reached. Few cases of grade 3 treatment-related AEs, but no grade 4 AEs occurred in the combination arms (48).

Necitumumab is a second-generation, recombinant human IgG1 mAb to EGFR. Two randomized controlled trials, INSPIRE and SQUIRE, indicated that necitumumab with gemcitabine and cisplatin as a first-line therapy improved OS in treatment-naïve patients with advanced SqNSCLC (11.5 vs. 9.9 months; $p=0.01$ ) but not in non-SqNSCLC treated with necitumumab with pemetrexed and cisplatin (49, 50). Combination therapy of necitumumab and pembrolizumab is currently being studied for safety and efficacy in patients with advanced SqNSCLC and non-SqNSCLC in a phase I study (51).

Tables V and VI summarize the completed and ongoing clinical trials, respectively, for PD-1/PD-L1 inhibitors as combination therapy in NSCLC.

\section{Cytotoxic T-Lymphocyte-associated Protein 4 (CTLA-4) in NSCLC}

CTLA-4 is expressed exclusively on T-cells. Both CTLA-4 and T-cell co-stimulatory CD28 receptor expressed on antigenpresenting cells share the same ligands (CD80 and CD86). However, CTLA-4 has a much higher affinity for both CD80 and CD86, which makes it compete with CD28 in binding to 
Table V. Clinical trials for programmed cell death protein 1/programmed cell death ligand 1 (PD-1/PD-L1) inhibitors as combination therapy in non-small cell lung cancer (NSCLC).

\begin{tabular}{lcccc}
\hline Study name & Agents & Phase & Stage/line & Outcomes \\
\hline $\begin{array}{l}\text { AVAPERL (47) } \\
(48)\end{array}$ & BEV +PEM & III & Advanced non-SqNSCLC & Median PFS improved from 3.7 to 7.4 months \\
ORR=8\% vs. 10\% with NVB alone
\end{tabular}

BEV: Bevacizumab. PEM: pemetrexed; NVB: nivolumab; NEC: necitumumab; CIS: cisplatin; GEM: gemcitabine; (non-) SqNSCLC: (non-) squamous NSCLC; PFS: progression-free survival; Pt: platinum; ORR: overall response rate; OS: overall survival.

Table VI. Ongoing clinical trials for programmed cell death protein 1/programmed cell death ligand 1 inhibitors as combination therapy in nonsmall cell lung cancer (NSCLC).

\begin{tabular}{|c|c|c|c|c|c|c|}
\hline Study name & Study identifier & Agents & Phase & Stage/line & Outcomes & Grade 3-4 AEs \\
\hline KEYNOTE-021 (37) & NCT02039674 & Pembrolizumab+Pt & $\mathrm{I} / \mathrm{II}$ & $\begin{array}{l}\text { Unresectable or } \\
\text { metastatic }\end{array}$ & $\begin{array}{c}\text { ORR }=30 \% \text { in any } \\
\text { histology and } 58 \% \text { in } \\
\text { nonSqNSCLC positive } \\
\text { for } E G F R \text { or } A L K\end{array}$ & $\begin{array}{l}\text { Reversible AST/ALT } \\
\text { elevation, anemia, } \\
\text { rash, and colitis }\end{array}$ \\
\hline (38) & NCT02382406 & MK-3475+CPT/Nab-PAC & $\mathrm{I} / \mathrm{II}$ & $\begin{array}{c}\text { Previously untreated } \\
\text { advanced }\end{array}$ & No results yet & No results yet \\
\hline (39) & NCT02422381 & MK-3475+GEM & $\mathrm{I} / \mathrm{II}$ & $\begin{array}{c}\text { Previously treated } \\
\text { advanced }\end{array}$ & No results yet & No results yet \\
\hline (40) & NCT01633970 & MPDL3280A+Pt & I & $\begin{array}{l}\text { Locally advanced or } \\
\text { metastatic solid tumors }\end{array}$ & $\begin{array}{c}\text { ORR }=67 \% \text { in first } \\
37 \text { patients }\end{array}$ & $\begin{array}{l}\text { Anemia, neutropenia } \\
\text { and thrombocytopenia }\end{array}$ \\
\hline CheckMate 012 (16) & NCT01454102 & Nivolumab+Ctx & I & Advanced & ORR $=33-47 \%$ & $\begin{array}{c}\text { Pneumonitis, fatigue } \\
\text { and ARF }\end{array}$ \\
\hline (46) & NCT02088112 & MEDI4736+GEF & I & $\begin{array}{l}\text { Locally advanced/ } \\
\text { metastatic, any } \\
E G F R \text { status }\end{array}$ & $\begin{array}{c}\text { Of } 7 \text { patients with } \geq 1 \\
\text { 8-week tumor assessment; } \\
3 \text { had reduction } \\
\text { in tumor size }\end{array}$ & $\begin{array}{c}\text { Dyspnea/hypoxia, } \\
\text { myalgia/fatigue, } \\
\text { and elevated ALT }\end{array}$ \\
\hline (51) & NCT02451930 & $\begin{array}{l}\text { Pembrolizumab+ } \\
\text { necitumumab }\end{array}$ & I & Stage IV & No results yet & No results yet \\
\hline
\end{tabular}

AEs: Adverse events; non-SqNSCLC: non-squamous NSCLC; Pt: platinum-based chemotherapy; Ctx: Chemotherapy; ORR: overall response rate; GEM: Gemcitabine; GEF: gefitinib; EGFR: epidermal growth factor receptor; ALK: anaplastic lymphoma kinase; ALT: alanine aminotransferase; AST: aspartate aminotransferase.

these ligands. This results in inhibition of CD28 stimulatory effect on T-cells $(52,53)$. CTLA-4 regulates the early stage of T-cell activation through additional mechanisms, including recruitment and activation of the Src homology region 2 domain-containing phosphatase-2 (SHP2) and protein phosphatase 2A (PP2A) via the YVKM motif in its cytoplasmic domain. This results in attenuation of kinase signaling, such as phosphatidylinositol-3 kinase/protein kinase $\mathrm{B}$ (PKB) also known as Akt pathway, induced by T-cell receptor and CD28. CTLA-4 primarily regulates CD4 ${ }^{+}$T-cells by down-regulating the activity of T-helper cells and enhancing the immunosuppressive activity of T-regulatory cells $(54,55)$.
Ipilimumab. Ipilimumab is an antibody against CTLA-4 approved for the treatment of metastatic melanoma (56). Its activity is under investigation for NSCLC.

A phase II trial of ipilimumab in combination with chemotherapy published some preliminary results. Patients with previously untreated metastatic NSCLC were randomly assigned to one of three groups: carboplatin-paclitaxel, carboplatin-paclitaxel with concurrent ipilimumab, or carboplatin-paclitaxel with sequential ipilimumab (57). Results were very promising, with a statistically significant improvement in PFS in the sequential arm (carboplatin and paclitaxel for two cycles followed by addition of ipilimumab 
with chemotherapy for four more cycles) compared to the chemotherapy alone arm (median PFS of $5.1 \mathrm{vs} .4 .2$ months, $p=0.02$ ). Subset analysis showed a greater benefit in patients with squamous histology and thus, a phase III study of ipilimumab in combination with carboplatin and paclitaxel for squamous cell carcinoma of the lung is ongoing (NCT 02279732) (58). Ipilimumab is also being studied in NSCLC in combination with radiation (NCT02239900, NCT02221739) $(59,60)$ and with other immunotherapy agents (NCT02039674, NCT02174172) $(61,62)$

PD-1/PD-L1 blockade in combination with CTLA-4 inhibitors. A phase III trial to evaluate the efficacy and safety of durvalumab as third-line monotherapy (substudy A, PDL1-positive) plus tremelimumab (substudy B, PD-L1negative) versus standard of care (including erlotinib, gemcitabine, or vinorelbine) in patients with stage IIIB/IV NSCLC is currently being conducted (34).

\section{Vaccines in NSCLC}

The role of vaccination in cancer stems from the antigens uniquely expressed on tumor cells. Vaccines have been increasingly studied in NSCLC (63).

The START trial investigated tecemotide (L-BLP25), a vaccine against MUC1 (a transmembrane mucin family protein), in patients with stage III NSCLC who had completed chemoradiation. MUC1 is a tumor-associated antigen overexpressed in lung cancer and other epithelial tumors. MUC1 immunogenicity stems from an aberrant glycosylation of this protein in tumor tissues compared to normal tissues. There were 1,513 patients enrolled without progressive disease randomized to receive either tecemotide or placebo. The primary endpoint of the study was OS. There was no significant difference in survival between the two arms (median OS of 25.6 months with tecemotide versus 22.3 months with placebo), although there was a benefit for the vaccine in patients who received concurrent rather than sequential chemotherapy (30.8vs. 20.6 months, $p=0.0175$ ). These promising results were not confirmed in other studies, and development of this compound has been halted (64).

In the MAGRIT trial, patients with surgically resected stage IB-IIIA NSCLC were randomized to receive placebo or a vaccine to melanoma-associated antigen 3 (MAGE-A3). Eligible patients were required to have MAGE-A3-positive tumors. A total of 2,272 patients were randomized and treated. Treatment was well tolerated but results were disappointing as the trial showed no significant improvement in disease-free survival (60.5 versus 57.9 months, $p=0.7379$ ) (65).

TG4010 is a recombinant modified vaccinia Ankara that codes for MUC1 and interleukin-2 (66). MUC1 encoded by TG4010 shares epitopes with tumor-associated MUC1.
The combination of TG4010 with first-line chemotherapy for advanced NSCLC has been studied in two randomized clinical trials. Findings from these studies were promising $(67,68)$.

The TIME trial was a phase IIb/III trial to assess TG4010 in combination with first-line chemotherapy. The trial concluded that TG4010 plus chemotherapy seems to improve PFS relative to placebo plus chemotherapy (69).

\section{Conclusion}

As a result of the success of multiple antibody inhibitors of PD-1/PD-L1 and CTLA-4 in clinical studies, immunotherapy has become an intriguing field for investigation in therapy for NSCLC. These therapeutic modalities have shown efficacy as first-, second-, and even third-line treatment in patients with NSCLC. Further research is needed to determine the best sequence of use of these agents and to identify the unique characteristics of those patients with durable remissions.

\section{References}

1 Jemal A, Bray F, Center MM, Ferlay J, Ward E and Forman D: Global cancer statistics. CA Cancer J Clin 61(2): 69-90, 2011.

2 Goldstraw P, Ball D, Jett JR, Le Chevalier T, Lim E, Nicholson AG and Shepherd FA: Non-small-cell lung cancer. Lancet 378(9804): 1727-1740, 2011

3 Siegel R, Ward E, Brawley O and Jemal A: Cancer statistics. CA Cancer J Clin 61(4): 212-236, 2011.

4 National Cancer Institute: PDQ ${ }^{\circledR}$ Non-Small Cell Lung Cancer Treatment. Bethesda, MD: National Cancer Institute. Date last modified <05/12/2015>. Available at: http://www.cancer.gov/ types/lung/patient/non-small-cell-lung-treatment-pdq. Accessed $<01 / 18 / 2016>$.

5 Schadendorf D, Hodi FS, Robert C, Weber JS, Margolin K, Hamid O, Patt D, Chen TT, Berman DM and Wolchok JD: Pooled analysis of long-term survival data from phase II and phase III trials of ipilimumab in unresectable or metastatic melanoma. J Clin Oncol 33: 1889-1894, 2015.

6 Jing W, Li M, Zhang Y, Teng F, Han A, Kong L and Zhu H: PD1/PD-L1 blockades in non-small-cell lung cancer therapy. Onco Targets Ther 9: 489-502, 2016.

7 Keir ME, Butte MJ, Freeman GJ and Sharpe AH: PD-1 and its ligands in tolerance and immunity. Annu Rev Immunol 26: 677704, 2008.

8 Sundar R, Cho BC, Brahmer JR and Soo RA: Nivolumab in NSCLC: latest evidence and clinical potential. Ther Adv Med Oncol 7(2): 85-96, 2015.

9 Sheppard KA, Fitz LJ, Lee JM, Benander C, George JA, Wooters J, Qiu Y, Jussif JM, Carter LL, Wood CR and Chaudhary D: PD1 inhibits T-cell receptor induced phosphorylation of the ZAP70/CD3 3 signalosome and downstream signaling to PKC $\theta$. FEBS Lett 574(1-3): 37-41, 2004.

10 Eisenhauer E, Therasse P, Bogaerts J, Schwartz LH, Sargent D, Ford R, Dancey J, Arbuck S, Gwyther S, Mooney M and Rubinstein L: New response evaluation criteria in solid tumours: revised RECIST guideline (version 1.1). Eur J Cancer 45(2): 228-247, 2009 
11 Oxnard GR, Morris MJ, Hodi FS, Baker LH, Kris MG, Venook AP and Schwartz LH: When Progressive Disease Does Not Mean Treatment Failure: Reconsidering the Criteria for Progression. J Natl Cancer Inst 104(20): 1534-1541, 2012.

12 Rizvi NA, Mazières J, Planchard D, Stinchcombe TE, Dy GK, Antonia SJ, Horn L, Lena H, Minenza E, Mennecier B and Otterson GA: Activity and safety of nivolumab, an anti-PD-1 immune checkpoint inhibitor, for patients with advanced, refractory squamous non-small-cell lung cancer (CheckMate 063): a phase 2, single-arm trial. Lancet Oncol 16(3): 257-265, 2015.

13 Bauer TM, McCleod M, Chandler JC, Blumenschein GR, Schwartzberg LS, Burris H, Waterhouse D, Jotte RM, Hussein $M$ and Spigel DR: An ongoing phase IIIb/IV safety trial of nivolumab (NIVO) in patients (pts) with advanced or metastatic non-small-cell lung cancer (NSCLC) who progressed after receiving 1 or more prior systemic regimens. J Clin Oncol 33(15 Suppl): 3013, 2015.

14 Brahmer J, Reckamp KL, Baas P, Crinò L, Eberhardt WE, Poddubskaya E, Antonia S, Pluzanski A, Vokes EE, Holgado E and Waterhouse D: Nivolumab versus docetaxel in advanced squamous-cell non-small-cell lung cancer. N Engl J Med 373(2): 123-135, 2015.

15 Paz-Ares L, Horn L, Borghaei H, Spigel DR, Steins M, Ready N, Chow LQ, Vokes EE, Felip E, Holgado E and Barlesi F: Phase III, randomized trial (CheckMate 057) of nivolumab (NIVO) versus docetaxel (DOC) in advanced non-squamous cell (non-SQ) non-small cell lung cancer (NSCLC). J Clin Oncol 33(18 Suppl): LBA109, 2015.

16 Antonia SJ, Brahmer JR, Gettinger S, Chow LQ, Juergens R, Shepherd FA, Laurie SA, Gerber DE, Goldman J, Shen Y and Harbison C: Nivolumab (anti-PD-1; BMS-936558, ONO-4538) in combination with platinum-based doublet chemotherapy (PTDC) in advanced non-small cell lung cancer (NSCLC). J Clin Oncol 32(15 Suppl): 8113, 2014.

17 Wolchok JD, Hoos A, O’Day S, Weber JS, Hamid O, Lebbé C, Maio M, Binder M, Bohnsack O, Nichol G and Humphrey R: Guidelines for the evaluation of immune therapy activity in solid tumors: Immune-related response criteria. Clin Cancer Res 15: 7412-7420, 2009.

18 Garon EB, Rizvi NA, Hui R, Leighl N, Balmanoukian AS, Eder JP, Patnaik A, Aggarwal C, Gubens M, Horn L and Carcereny E: Pembrolizumab for the treatment of Non-Small-cell lung cancer. N Engl J Med 372(21): 2018-2028, 2015.

19 Santarpia M, González-Cao M, Viteri S, Karachaliou N, Altavilla $\mathrm{G}$ and Rosell R: Programmed cell death protein1/programmed cell death ligand-1 pathway inhibition and predictive biomarkers: understanding transforming growth factor-beta role. Transl Lung Cancer Res 4(6): 728-742, 2015.

20 Postow MA, Callahan MK and Wolchok JD: Immune Checkpoint Blockade in Cancer Therapy. J Clin Oncol 33(17): 1974-1982, 2015.

21 Topalian SL, Hodi FS, Brahmer JR, Gettinger SN, Smith DC, McDermott DF, Powderly JD, Carvajal RD, Sosman JA, Atkins MB and Leming PD: Safety, activity, and immune correlates of anti-PD-1 antibody in cancer. N Engl J Med 366(26): 24432454, 2012.

22 Gettinger SN, Horn L, Gandhi L, Spigel DR, Antonia SJ, Rizvi NA, Powderly JD, Heist RS, Carvajal RD, Jackman DM and Sequist LV: Overall survival and long-term safety of nivolumab (anti-programmed death 1 antibody, BMS-936558, ONO-4538) in patients with previously treated advanced non-small-cell lung cancer. J Clin Oncol 33(18): 2004-2012, 2015.

23 European Thoracic Oncology Platform Nivolumab consolidation after standard first-line chemotherapy and radiotherapy in locally advanced stage IIIA/B NSCLC (NICOLAS) [Accessed November 28, 2015]. Available from: https://www.clinical trials.gov/show/NCT02434081. NLM identifier: NCT02434081.

24 Gettinger SN, Hellmann MD, Shepherd FA, Antonia SJ, Brahmer JR, Chow LQ, Goldman JW, Juergens RA, Borghaei H and Ready N: First-line mono- therapy with nivolumab (NIVO; anti-programmed death-1 [PD-1]) in advanced non-small cell lung cancer (NSCLC): safety, efficacy and correlation of outcomes with PD-1 ligand (PD-L1) expression. J Clin Oncol 33(15 Suppl): 8025, 2015.

25 Herbst RS, Baas P, Kim DW, Felip E, Pérez-Gracia JL, Han JY, Molina J, Kim JH, Arvis CD, Ahn MJ and Majem M: Pembrolizumab versus docetaxel for previously treated, PD-L1positive, advanced non-small-cell lung cancer (KEYNOTE-010): a randomised controlled trial. Lancet 10: 6736, 2015.

26 Nasser Hanna MD: Consolidation pembrolizumab (MK-3475) following chemoradiation in patients with inoperable/ unresectable stage III NSCLC. Available from: https:// www.clinicaltrials.gov/ct2/show/NCT02343952. NLM identifier: NCT02343952. Accessed November 28, 2015.

27 The Netherlands Cancer Institute. Pembrolizumab after SBRT versus pembrolizumab alone in advanced NSCLC (PEMBRORT). Available from: https://www.clinicaltrials.gov/ct2/show/ NCT02492568. NLM identifier: NCT02492568. Accessed November 28, 2015.

28 Merck Sharp \& Dohme Corp. Study of MK-3475 (pembrolizumab) versus platinum-based chemotherapy for participants with PD-L1-positive advanced or metastatic nonsmall cell lung cancer (MK-3475-042/KEYNOTE-042). Available from: https://www.clinicaltrials.gov/ct2/ show/NCT02 220894. NLM identifier: NCT02220894. Accessed November $28,2015$.

29 Reck M, Rodríguez-Abreu D, Robinson AG, Hui R, Csőszi T, Fülöp A, Gottfried M, Peled N, Tafreshi A, Cuffe S and O'Brien M: Pembrolizumab versus Chemotherapy for PD-L1-Positive Non-Small-Cell Lung Cancer. N Engl J Med 375(19): 1823$1833,2016$.

30 Fehrenbacher L, Spira A, Ballinger M, Kowanetz M, Vansteenkiste J, Mazieres J, Park K, Smith D, Artal-Cortes A, Lewanski C and Braiteh F: Atezolizumab versus docetaxel for patients with previously treated non-small-cell lung cancer (POPLAR): a multicentre, open-label, phase 2 randomised controlled trial. Lancet 387(10030): 1837-1846, 2016.

31 Hoffman-La Roche. A Randomized Phase 3 Study of Atezolizumab (an Engineered Anti-PDL1 Antibody) Compared to Docetaxel in Patients With Locally Advanced or Metastatic Non-Small Cell Lung Cancer Who Have Failed Platinum Therapy - "OAK". Available from: https://clinicaltrials.gov/ ct2/show/record/NCT02008227. Accessed October 22, 2016.

32 Spigel DR, Chaft JE, Gettinger SN, Chao BH, Dirix LY, Schmid P, Chow LQ, Chappey C, Kowanetz M and Sandler A: Clinical activity and safety from a phase II study (FIR) of MPDL3280A (anti-PDL1) in PD-L1-selected patients with non-small cell lung cancer (NSCLC). J Clin Oncol 33(15 Suppl): 8028, 2015. 
33 Rizvi NA, Chow LQ, Dirix LY, Gettinger SN, Gordon MS, Kabbinavar FF, Von Pawel J, Soria JC, Chappey C, Mokatrin A and Sandler A: Clinical trials of MPDL3280A (anti-PDL1) in patients (pts) with non-small cell lung cancer (NSCLC). J Clin Oncol 32(15 Suppl): TPS8123, 2014.

34 AstraZeneca. A global study to assess the effects of MEDI4736 in patients with locally advanced or metastatic non small cell lung cancer (ATLANTIC). Available from: https:// www.clinicaltrials.gov/ct2/show/NCT02087423. NLM identifier: NCT02087423. Accessed November 28, 2015.

35 AstraZeneca. A global study to assess the effects of MEDI4736, given as monotherapy or in combination with tremelimumab determined by PD-L1 expression versus standard of care in patients with locally advanced or metastatic non small cell lung cancer (ARCTIC). Available from: https://www.clinical trials.gov/ct2/show/NCT02352948. NLM identifier: NCT0235 2948. Accessed November 28, 2015.

36 Brahmer JR, Tykodi SS, Chow LQ, Hwu WJ, Topalian SL, Hwu P, Drake CG, Camacho LH, Kauh J, Odunsi K and Pitot HC: Safety and Activity of Anti-PD-L1 Antibody in Patients with Advanced Cancer. N Engl J Med 366(26): 2455-2465, 2012.

37 Papadimitrakopoulou V, Patnaik A, Borghaei H, Stevenson J, Gandhi L, Gubens MA, Yang JC, Sequist LV, Ge JY and Bourque J: Pembrolizumab (pembro; MK-3475) plus platinum doublet chemotherapy (PDC) as front-line therapy for advanced non-small cell lung cancer (NSCLC): KEYNOTE-021 Cohorts A and C. J Clin Oncol 33(15 Suppl): 8031, 2015.

38 Jyoti Patel. Carboplatin/Nab-Paclitaxel and MK-3475 in NSCLC. Available from: https://www.clinicaltrials.gov/ct2/ show/NCT02382406. NLM identifier: NCT02382406. Accessed November 28, 2015.

39 Providence Health \& Services. MK-3475 and gemcitabine in non-small cell lung cancer (NSCLC). Available from: https://www.clinicaltrials.gov/ct2/show/NCT02422381. NLM identifier: NCT02422381. Accessed November 28, 2015.

40 Liu SV, Powderly JD, Camidge DR, Ready N, Heist RS, Hodi FS, Giaccone G, Liu B, Wallin J and Funke RP: Safety and efficacy of MPDL3280A (anti-PDL1) in combination with platinum-based doublet chemotherapy in patients with advanced non-small cell lung cancer (NSCLC). J Clin Oncol 33(15 Suppl): 8030, 2015.

41 Chen N, Fang W, Zhan J, Hong S, Tang Y, Kang S, Zhang Y, He $\mathrm{X}$, Zhou T, Qin T and Huang Y: Upregulation of PD-L1 by EGFR activation mediates the immune escape in EGFR-driven NSCLC: implication for optional immune targeted therapy for NSCLC patients with EGFR mutation. J Thorac Oncol 10: 910923, 2015.

42 Akbay EA, Koyama S, Carretero J, Altabef A, Tchaicha JH, Christensen CL, Mikse OR, Cherniack AD, Beauchamp EM, Pugh TJ and Wilkerson MD: Activation of the PD-1 pathway contributes to immune escape in EGFR-driven lung tumors. Cancer Discov 3(12): 1355-1363, 2013.

43 D'incecco A, Andreozzi M, Ludovini V, Rossi E, Capodanno A, Landi L, Tibaldi C, Minuti G, Salvini J, Coppi E and Chella A: PD-1 and PD-L1 expression in molecularly selected nonsmall-cell lung cancer patients. Br J Cancer 112(1): 95-102, 2015.

44 Lin C, Chen X, Li M, Liu J, Qi X, Yang W, Zhang H, Cai Z, Dai $\mathrm{Y}$ and Ouyang $\mathrm{X}$ : Programmed death-ligand 1 expression predicts tyrosine kinase inhibitor response and better prognosis in a cohort of patients with epidermal growth factor receptor mutation-positive lung adenocarcinoma. Clin Lung Cancer 16(5): e25-e35, 2015.

45 Tang Y, Fang W, Zhang Y, Hong S, Kang S, Yan Y, Chen N, Zhan J, He X, Qin T and Li G: The association between PD-L1 and EGFR status and the prognostic value of PD-L1 in advanced non-small cell lung cancer patients treated with EGFR-TKIs. Oncotarget 6(16): 14209-14219, 2015.

46 Creelan BC, Chow LQ, Kim DW, Kim SW, Yeh $\mathrm{T}$ and Karakunnel JJ: Safety and tolerability results from a phase I study of MEDI4736, a human IgG1 anti-programmed cell deathligand-1 (PD-L1) antibody, combined with gefitinib in patients (pts) with non-small-cell lung cancer (NSCLC). J Clin Oncol 33(15 Suppl): 3047, 2015.

47 Barlesi F, Scherpereel A, Gorbunova V, Gervais R, Vikström A, Chouaid C, Chella A, Kim JH, Ahn MJ, Reck M and Pazzola A: Maintenance bevacizumab-pemetrexed after first-line cisplatinpemetrexed-bevacizumab for advanced nonsquamous nonsmallcell lung cancer: updated survival analysis of the AVAPERL (MO22089) randomized phase III trial. Ann Oncol 25(5): 10441052, 2014.

48 Rizvi NA, Antonia SJ, Shepherd FA, Chow LQ, Goldman J, Shen Y, Chen AC and Gettinger S: Nivolumab (Anti-PD-1; BMS-936558, ONO-4538) maintenance as monotherapy or in combination with bevacizumab (bevacizumab) for non-small cell lung cancer (NSCLC) previously treated with chemotherapy. Int J Radiat Oncol Biol Phys 90(5): S32, 2014.

49 Thatcher N, Hirsch FR, Luft AV, Szczesna A, Ciuleanu TE, Dediu M, Ramlau R, Galiulin RK, Bálint B, Losonczy G and Kazarnowicz A: Necitumumab plus gemcitabine and cisplatin versus gemcitabine and cisplatin alone as first-line therapy in patients with stage IV squamous non-small-cell lung cancer (SQUIRE): an open-label, randomised, controlled phase 3 trial. Lancet Oncol 16(7): 763-774, 2015.

50 Paz-Ares L, Mezger J, Ciuleanu TE, Fischer JR, von Pawel J, Provencio M, Kazarnowicz A, Losonczy G, de Castro G, Szczesna A and Crino L: Necitumumab plus pemetrexed and cisplatin as first-line therapy in patients with stage IV nonsquamous non-small-cell lung cancer (INSPIRE): an open-label, randomised, controlled phase 3 study. Lancet Oncol 16(3): 328337, 2015.

51 Eli Lilly and Company: A study of the combination of necitumumab (LY3012211) and pembrolizumab (MK3475) in participants with NSCLC. Available from: https:// www.clinicaltrials.gov/ct2/show/NCT02451930. NLM identifier: NCT02451930. Accessed November 28, 2015.

52 Pardoll DM: The blockade of immune checkpoints in cancer immunotherapy. Nat Rev Cancer 12(4): 252-264, 2012.

53 Lenschow DJ, Walunas TL and Bluestone JA: CD28/B7 system of T-cell costimulation. Annu Rev Immunol 14: 233-258, 1996.

54 Riley JL, Mao M, Kobayashi S, Biery M, Burchard J, Cavet G, Gregson BP, June CH and Linsley PS: Modulation of TCRinduced transcriptional profiles by ligation of CD28, ICOS, and CTLA-4 receptors. Proc Natl Acad Sci USA 99(18): 1179011795, 2002.

55 Parry RV, Chemnitz JM, Frauwirth KA, Lanfranco AR, Braunstein I, Kobayashi SV, Linsley PS, Thompson CB and Riley JL: CTLA-4 and PD-1 Receptors Inhibit T-Cell Activation by Distinct Mechanisms. Mol Cell Biol 25(21): 9543-9553, 2005. 
56 Hodi FS, O'day SJ, McDermott DF, Weber RW, Sosman JA, Haanen JB, Gonzalez R, Robert C, Schadendorf D, Hassel JC and Akerley W: Improved Survival with Ipilimumab in Patients with Metastatic Melanoma. N Eng J Med 363(8): 711-723, 2010.

57 Lynch TJ, Bondarenko I, Luft A, Serwatowski P, Barlesi F, Chacko R, Sebastian M, Neal J, Lu H, Cuillerot JM and Reck $\mathrm{M}$ : Ipilimumab in combination with paclitaxel and carboplatin as first-line treatment in stage IIIB/IV Non-Small-cell lung cancer: Results from a randomized, double-blind, multicenter phase II study. J Clin Oncol 30(17): 2046-2054, 2012.

58 Bristol-Myers Squibb. Phase 3 Trial in Squamous Non Small Cell Lung Cancer Subjects Comparing Ipilimumab Plus Paclitaxel and Carboplatin Versus Placebo Plus Paclitaxel and Carboplatin. Available from: https://clinicaltrials.gov/ct2/show/ NCT02279732. Accessed April 30, 2016.

59 M.D. Anderson Cancer Center. Ipilimumab and Stereotactic Body Radiation Therapy (SBRT) in Advanced Solid Tumors. Available from: https://clinicaltrials.gov/ct2/show/ NCT02239900. Accessed April 30, 2016.

60 New York University School of Medicine. Study of Combined Ionizing Radiation and Ipilimumab in Metastatic Non-small Cell Lung Cancer (NSCLC). Available from: https://clinicaltrials.gov/ ct2/show/NCT02221739. Accessed April 30, 2016.

61 Sharp \& Dohme Corp. A Study of Pembrolizumab (MK-3475) in Combination With Chemotherapy or Immunotherapy in Participants With Lung Cancer (MK-3475-021/KEYNOTE-021). Available from: https://clinicaltrials.gov/ct2/show/NCT0203 9674. Accessed April 30, 2016.

62 Hoffmann-La Roche. A Study to Assess the Safety and Tolerability of MPDL3280A in Combination With Other Immune-modulating Therapies in Patients With Locally Advanced or Metastatic Solid Tumors. Available from: https:// clinicaltrials.gov/ct2/show/NCT02174172. Accessed April 30, 2016.

63 Carrizosa DR and Gold KA: New strategies in immunotherapy for non-small cell lung cancer. Transl Lung Cancer Res 4(5): 553-559, 2015.
64 Butts C, Socinski MA, Mitchell PL, Thatcher N, Havel L, Krzakowski M, Nawrocki S, Ciuleanu TE, Bosquée L, Trigo JM and Spira A: Tecemotide (L-BLP25) versus placebo after chemoradiotherapy for stage III non-small-cell lung cancer (START): a randomised, double-blind, phase 3 trial. Lancet Oncol 15: 59-68, 2014.

65 Vansteenkiste JF, Cho B, Vanakesa T, De Pas T, Zielinski M, Kim MS, Jassem J, Yoshimura M, Dahabreh J, Nakayama H and Havel L: MAGRIT, a double-blind, randomized, placebocontrolled Phase III study to assess the efficacy of the recMAGE-A3 + A S15 cancer immunotherapeutic as adjuvant therapy in patients with resected MAGE-A3-positive non-small cell lung cancer. Ann Oncol 25: iv409, 2014.

66 Limacher JM and Quoix E: TG4010: A therapeutic vaccine against MUC1 expressing tumors. Oncoimmunology 1(5): 791792, 2012.

67 Quoix E, Ramlau R, Westeel V, Papai Z, Madroszyk A, Riviere A, Koralewski P, Breton JL, Stoelben E, Braun D and Debieuvre D: Therapeutic vaccination with TG4010 and first-line chemotherapy in advanced non-small-cell lung cancer: a controlled phase 2B trial. Lancet Oncol 12: 1125-1133, 2011.

68 Ramlau R, Quoix E, Rolski J, Pless M, Lena H, Lévy E, Krzakowski M, Hess D, Tartour E, Chenard MP and Limacher JM: A phase II study of TG4010 (MVA-MUC1-IL2) in association with chemotherapy in patients with stage III/IV nonsmall cell lung cancer. J Thorac Oncol 3: 735-744, 2008.

69 Quoix E, Lena H, Losonczy G, Forget F, Chouaid C, Papai Z, Gervais R, Ottensmeier C, Szczesna A, Kazarnowicz A and Beck JT: TG4010 immunotherapy and first-line chemotherapy for advanced non-small-cell lung cancer (TIME): Results from the phase $2 \mathrm{~b}$ part of a randomised, double-blind, placebo-controlled, phase 2b/3 trial. Lancet Oncol 17(2): 212-223, 2016.

Received December 31, 2016

Revised January 19, 2017

Accepted January 24, 2017 